\title{
POLYPOID DEGENERATION OF THE VOCAL CORD
}

\author{
By \\ HIDeo ISHII M.D. and TAxastr BABA \\ From the Department of Oto-Rhino-Laryngology. School \\ of Medicine, Gunna University.
}

\begin{abstract}
4 cases with severe diffuse edematous swelling were reported, which involved the whole of unila. teral or bilateral vocal cords.

The terminology of this condition was first discussed, since this pathological state as an entity has not yet been fully established here and abroad.

Secondary clinical symptoms of each case were presented in detail and examined from rarious viewpoints, such as age. sex, occupation, drinking and smoking, general conditions, progress, etc.

Third!y with regard to treatment surgical methods were prefered either indirectly by means of laryngoscope or directly through laryngofissure.
\end{abstract}

Conservative treatment was found to be not so effective. Prognosis was good in all cabes.

Finslly the results of histo-pathological examination was given. They were considerably different from the general polyp of the vocal cord and all these 4 cases presented a common feature+....-severe edena (which constitutes a prixipal lesion) and partially observable stight fibrosis and vascular regeneration. There was no plasma infiltration, fibrimoid depasition. In generel, ragodilatation, congestion, thrombwe formation and hemorrhage were slightly vigible or invisible. Inflammatory celiular infiltration was also of a low degree.

\section{声帯のポリーブ様変性について}

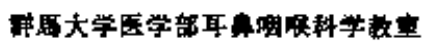

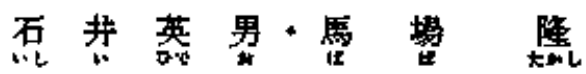

\section{I.}

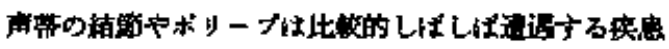

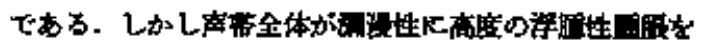

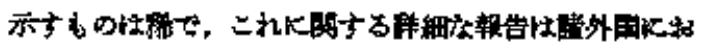

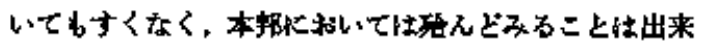

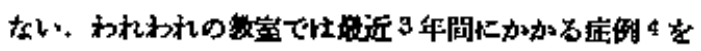
保したのC Holinger $\odot$ polypoid degeneration of

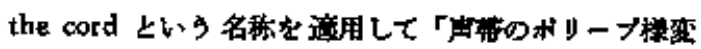

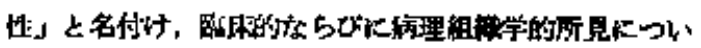

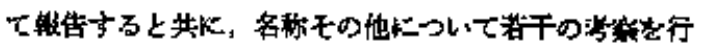
つてみた.

\section{I. 症例}

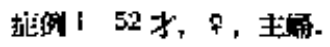

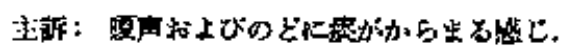

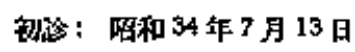

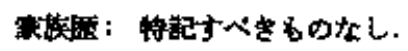

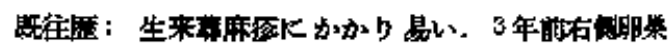

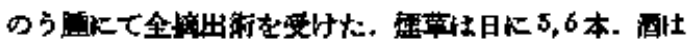
欽まない.

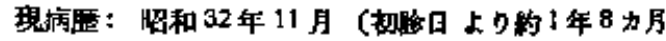

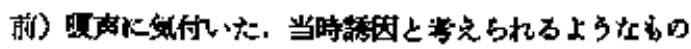

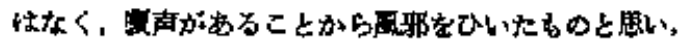

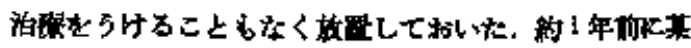

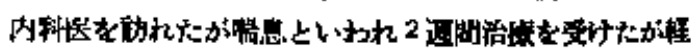

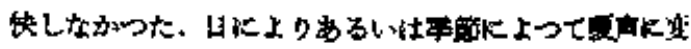
化をたたことはなかつた.

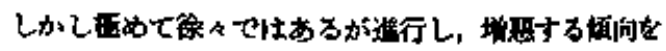

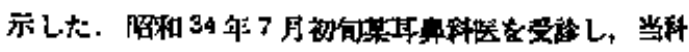

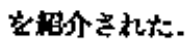

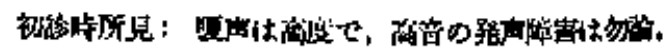




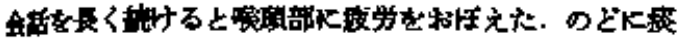

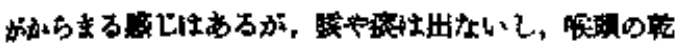

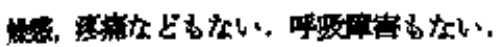

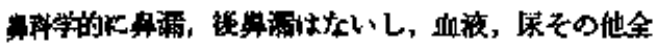

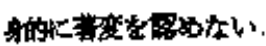

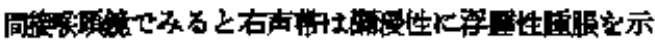

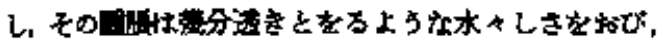

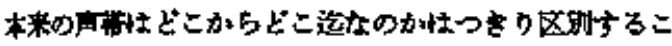

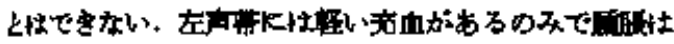

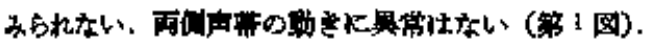

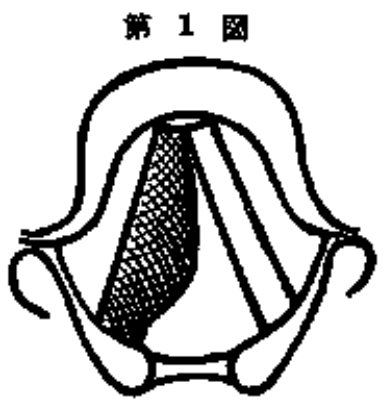

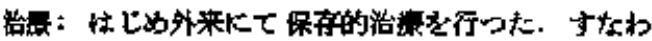

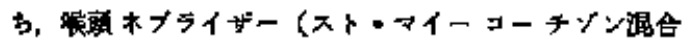

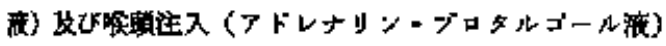

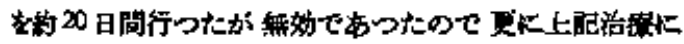

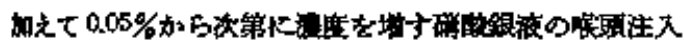

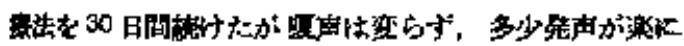

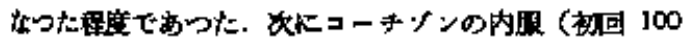

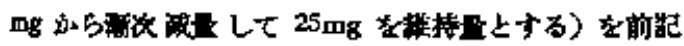

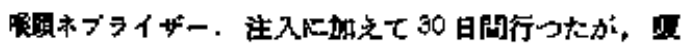

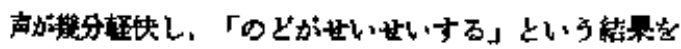

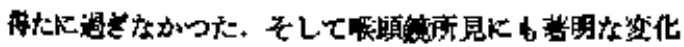

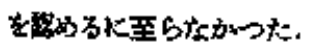

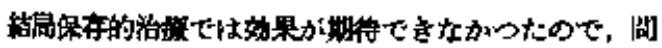

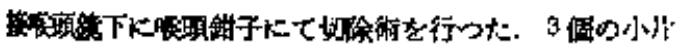

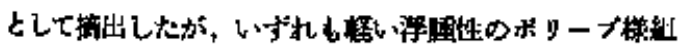

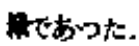

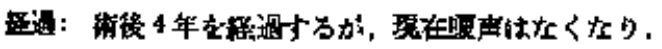

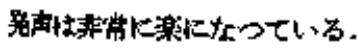

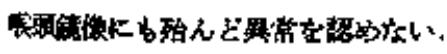

地列261才, 早, 主㧹。

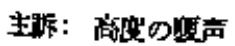

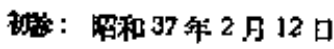

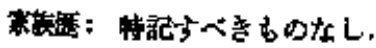

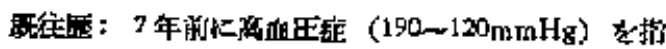

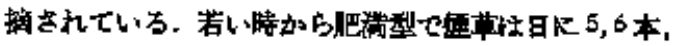

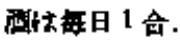

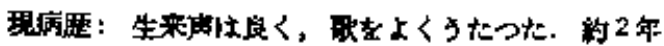

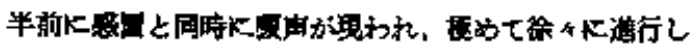

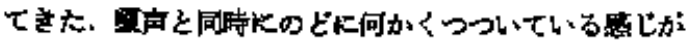
कot.

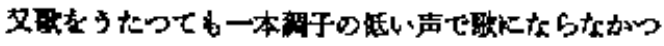

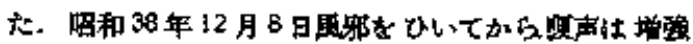

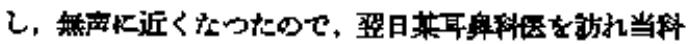
に积外をれた。

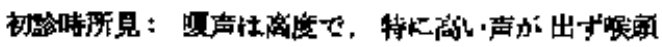

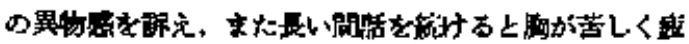

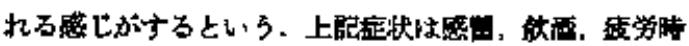

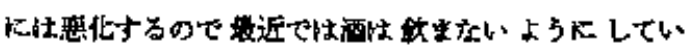

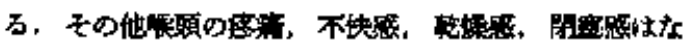

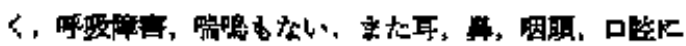
異常を鼓的ない。

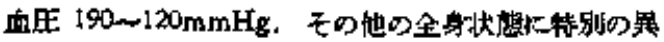

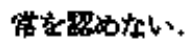

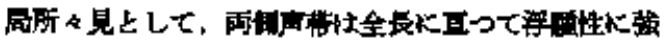

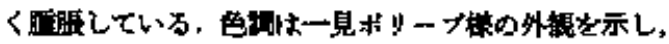

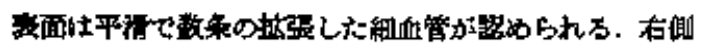

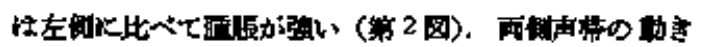

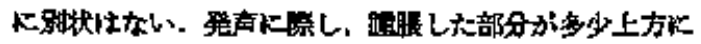

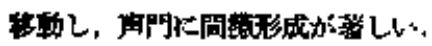

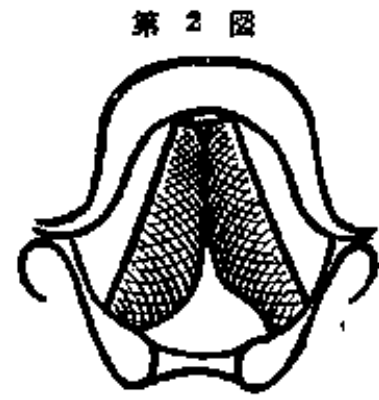

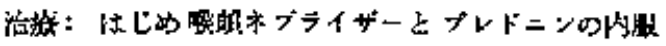

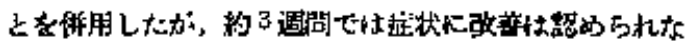

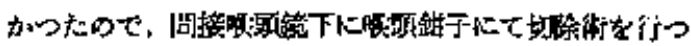

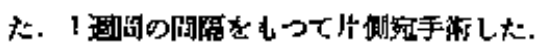

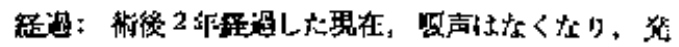

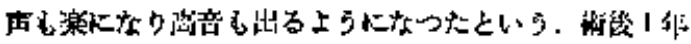

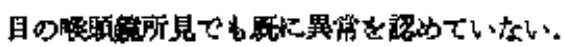


应例3 47 才。，9，莱败。

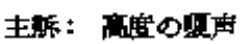

初移：噍和37年9月 28 日

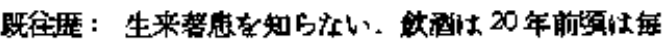

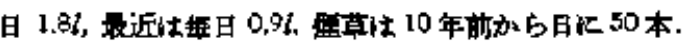

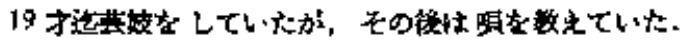

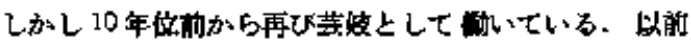

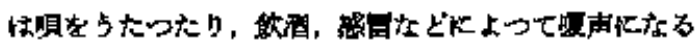
上ろたこと社加たという。

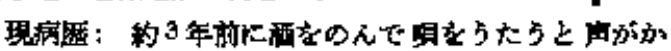

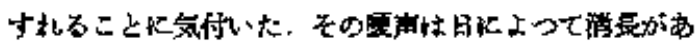

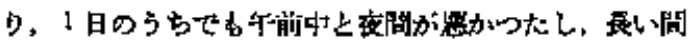

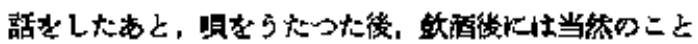
加的照化Lた.

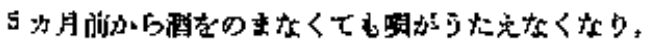

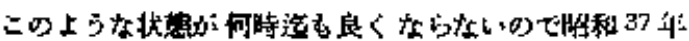

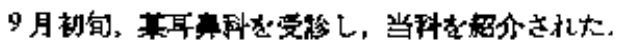

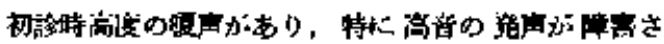

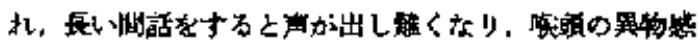

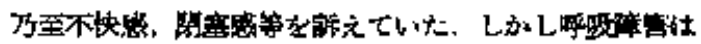

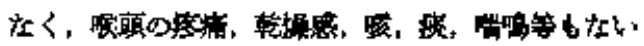

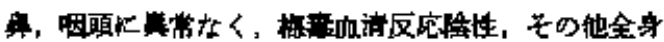

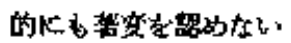

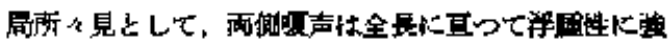

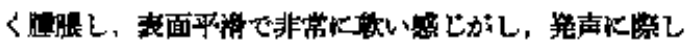

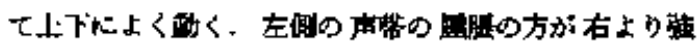

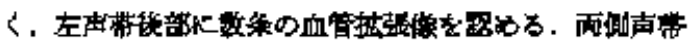

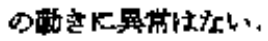

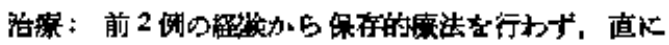

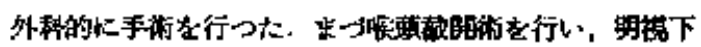

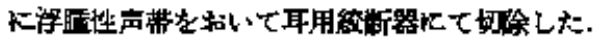

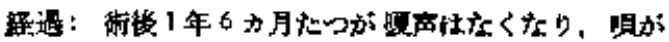
5たえる论炡块した。

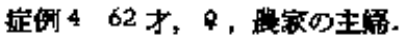

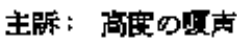

初的：昭和 38 年 10 月 14 日

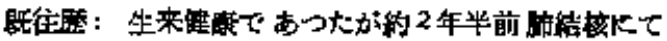

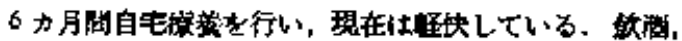

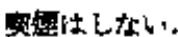

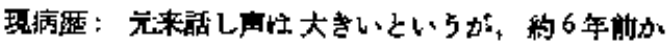

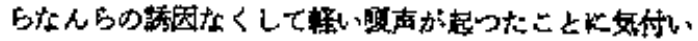

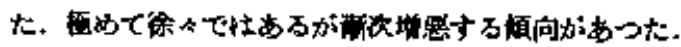

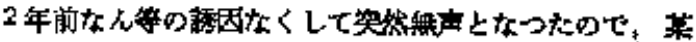

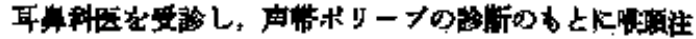

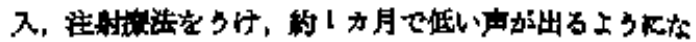

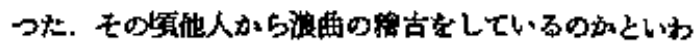
れたことがある。

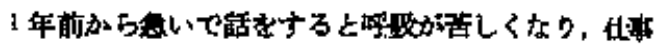

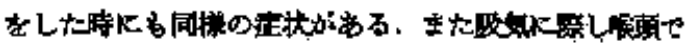

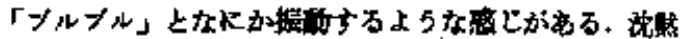

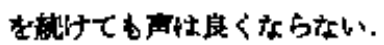

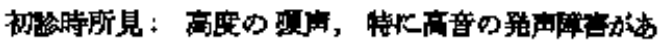

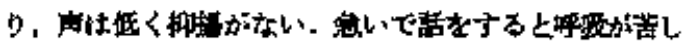

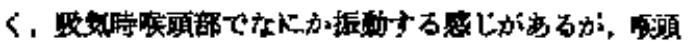

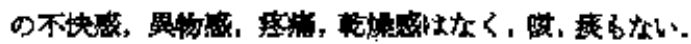

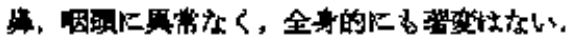

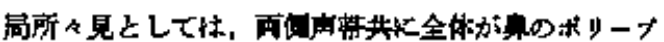

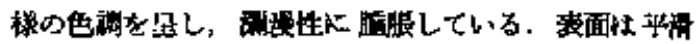

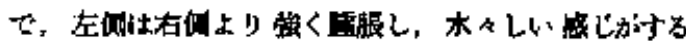

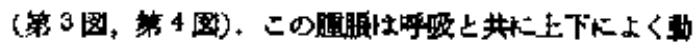

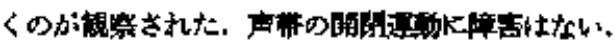

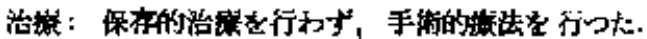

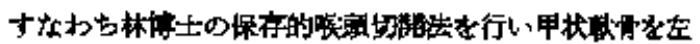

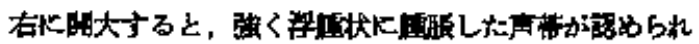

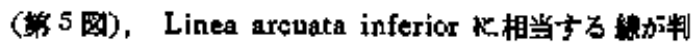
明したのて (桇6图)，提子にてがリーブあつかて，て

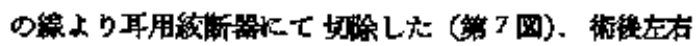

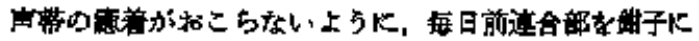
て用大した.

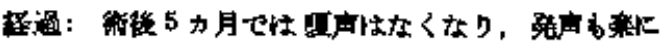

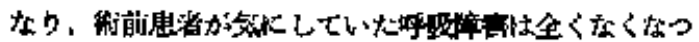
た.

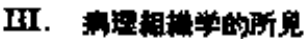

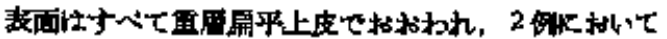

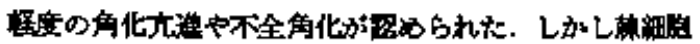

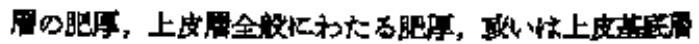

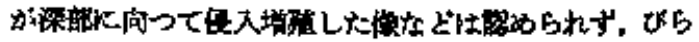

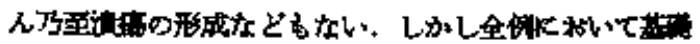

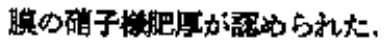

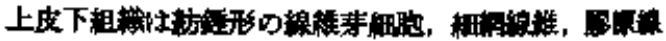

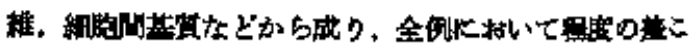

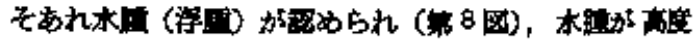

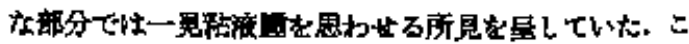

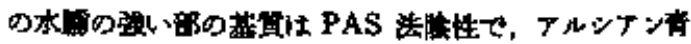

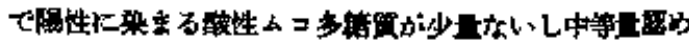
られた. 


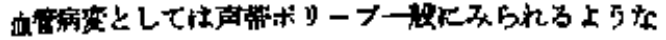

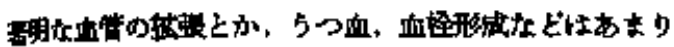

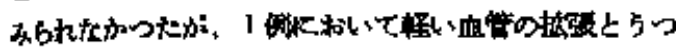

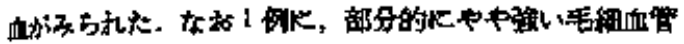

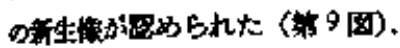

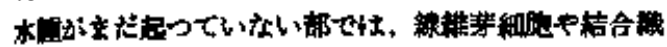

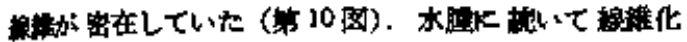

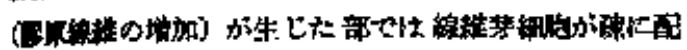
列儿大いた.

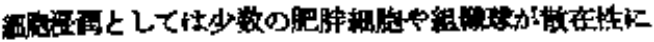

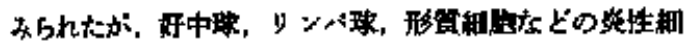

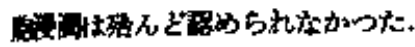

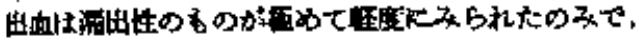

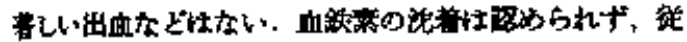

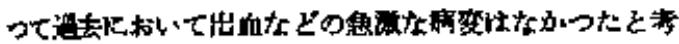
之られる.

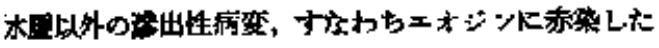

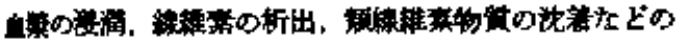

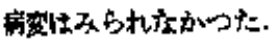

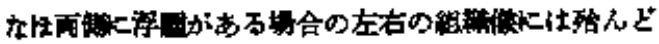
散县が加つ大.

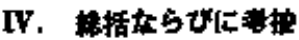

1) 名称について:

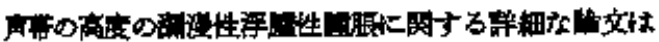

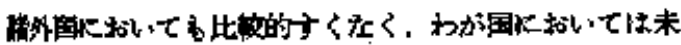

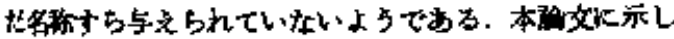

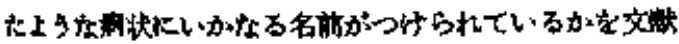


下列落してみ上马．

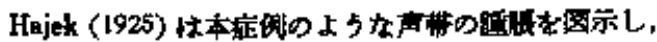
chrooische odematdse Hypertrophie der wahren

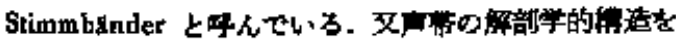
羽がした F. Reipke の功都をたたえて Reinkesches

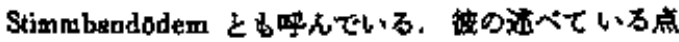

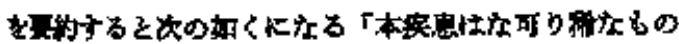

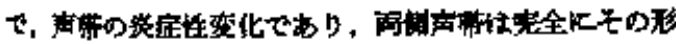

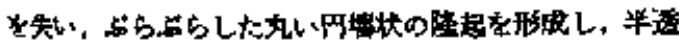

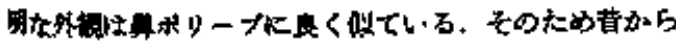

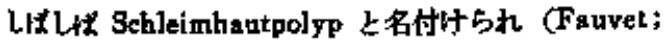

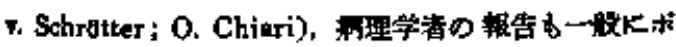

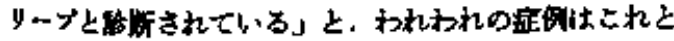
全く同したるる。
Blumenfeld (192B) it Dencker-Kahler $D$ Handbuch 中て, chorditis vocalis simplex 上い5费月のウ

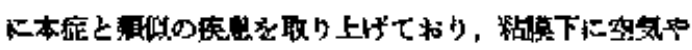



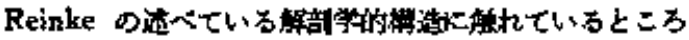

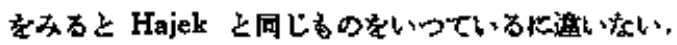

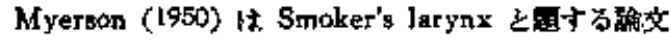

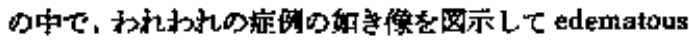

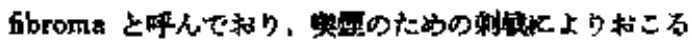

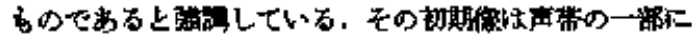

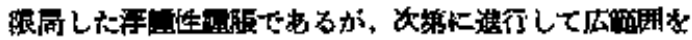

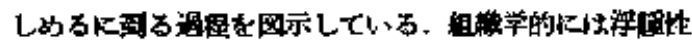

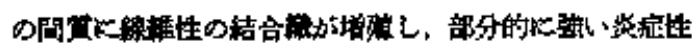

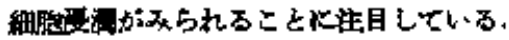

Holinger (1951) it polypoid degeneration of the

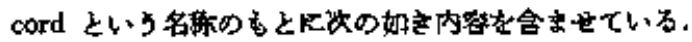
Thb ${ }^{*}$ the diffuse swelling of the estire length of one or both cords" tot味 L, polyp nodule $\zeta$

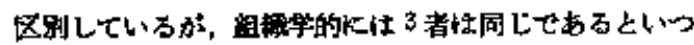

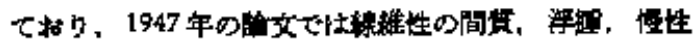

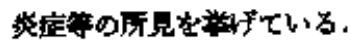

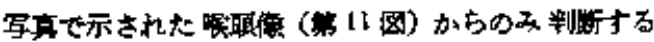

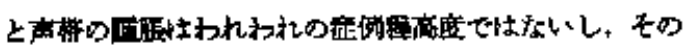

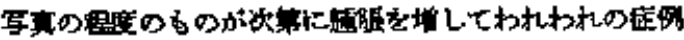

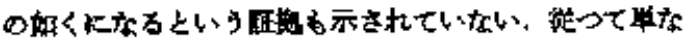

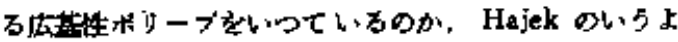

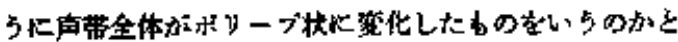


れの症例もこの中に入るものと思われる。

Epstein (1957) क polypoid degeneration $\measuredangle い 5$ 署

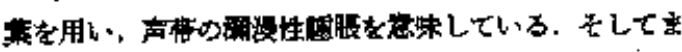

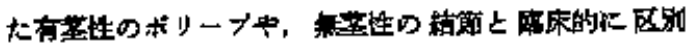

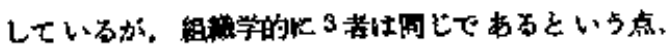
Holinger と同峦見である.

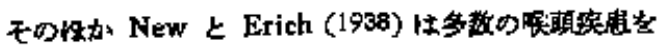

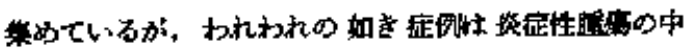
の polypoid tumor に入るよらである、しかしこれと myxomatous laryngeal neoplasm と注周一であると

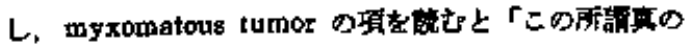

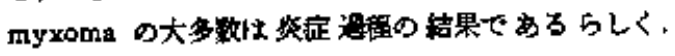

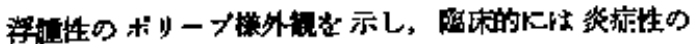
polypoid growth と区时大きたい」といいて和り。 


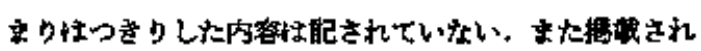

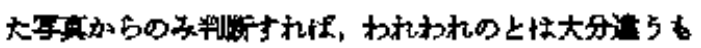
のといわきるを得たい、

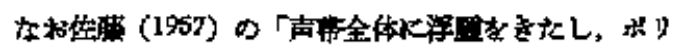

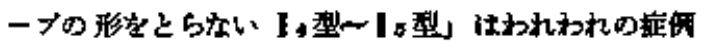

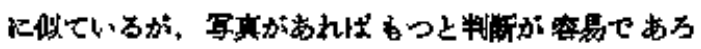
3.

以上のととが Reinkesches Stimmbandzdem, Schleimbautpolyp, Chorditis rocalis simplex, polypoid (3

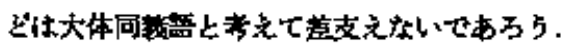

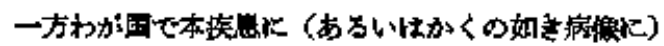

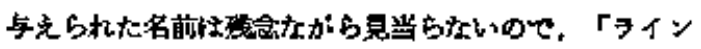

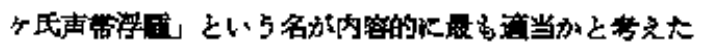

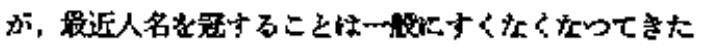
上S层のてt. Holinger $\sigma$ "polypaid degeneration of

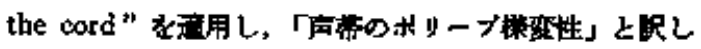

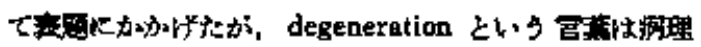

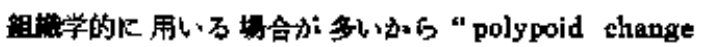

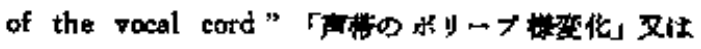

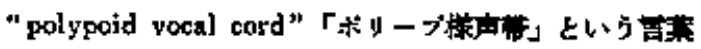

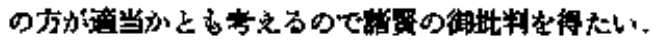

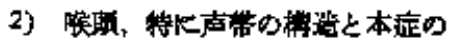
発生球峝上の网保

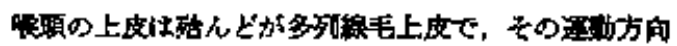

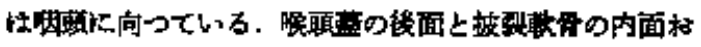

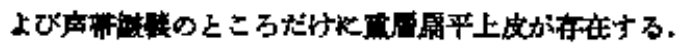

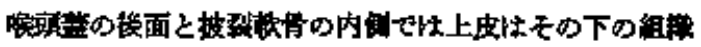

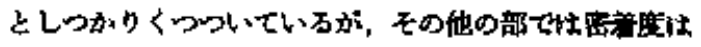

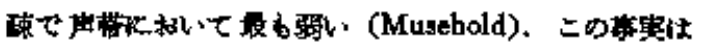

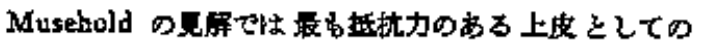

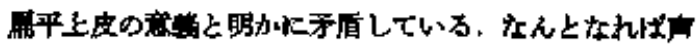

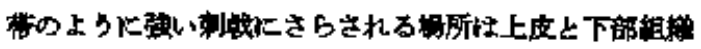

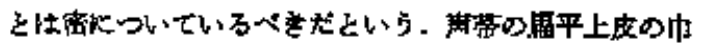

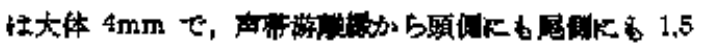

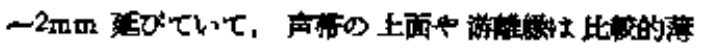

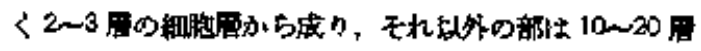

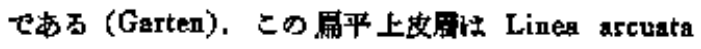

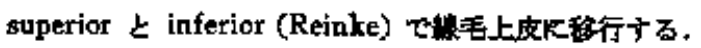

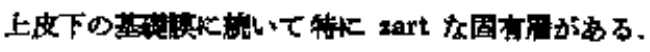

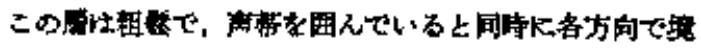

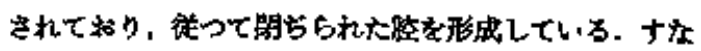
わち上下时前速の Linea arcuata であり, そこ社上皮

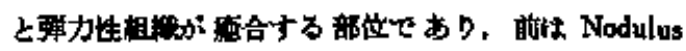
elasticus, 信仿 Proc voealis K反んでいる.

この有柜最初注目したのか Reinke (1695) て, “Re inke's layer or space" とか, "The space or triangle

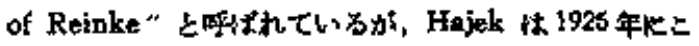

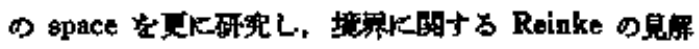

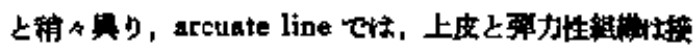
近していろに蛙ないといらた。

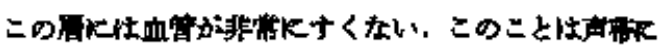

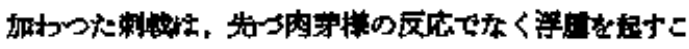

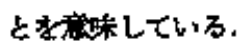

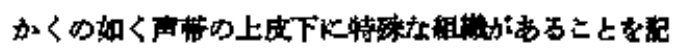

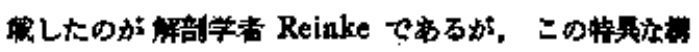

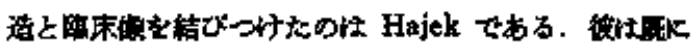

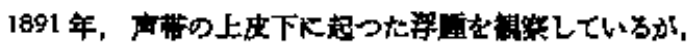

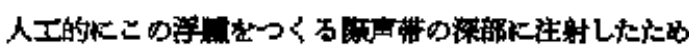

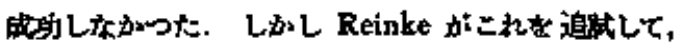

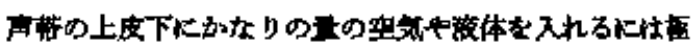

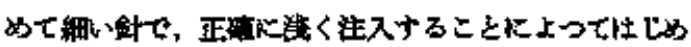

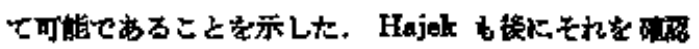

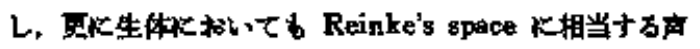

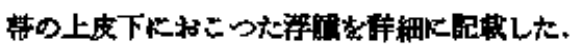

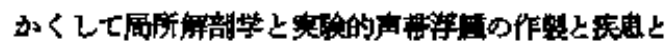

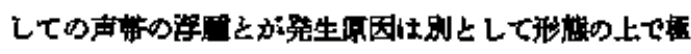
めて見本に結びかいたのある。

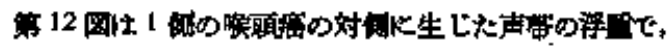

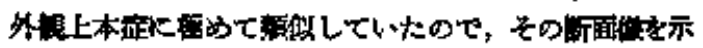
†

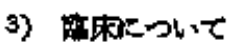

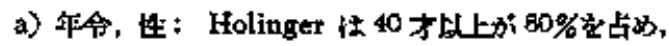
男性: 女性汒5：3てあるといら。

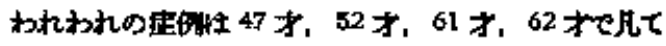

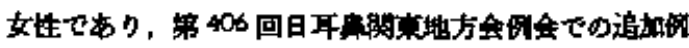

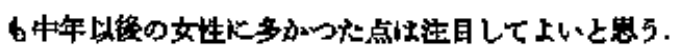

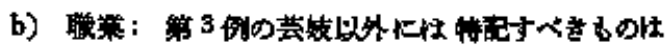

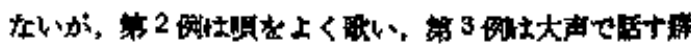

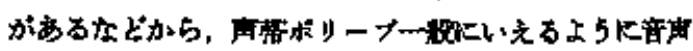

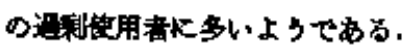

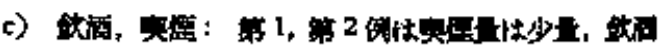

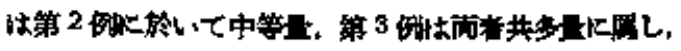

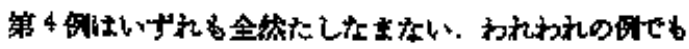

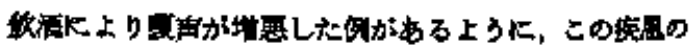

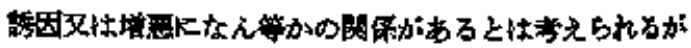




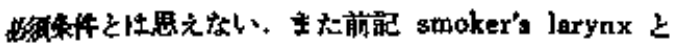

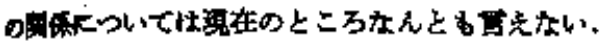

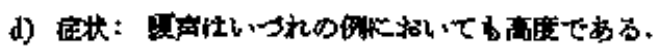

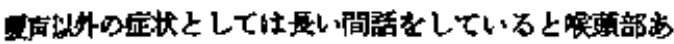

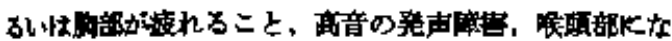

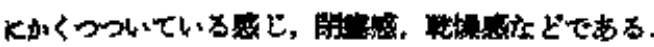

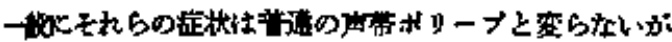

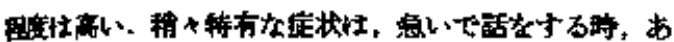

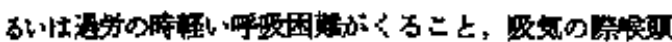

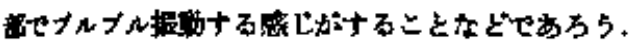

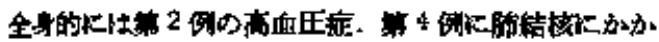

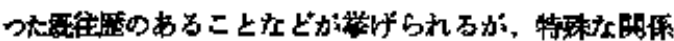

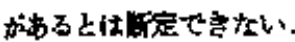

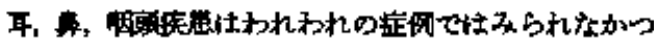

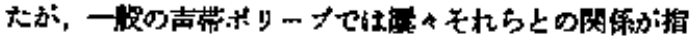

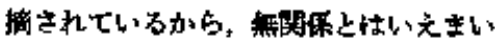

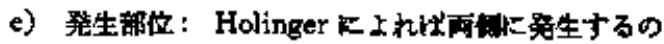

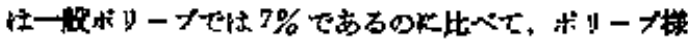

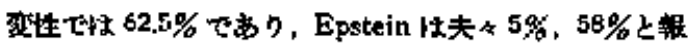

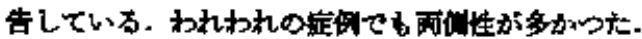

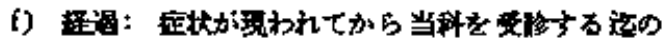

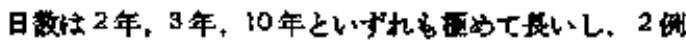

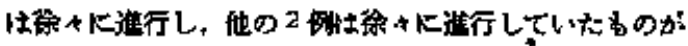

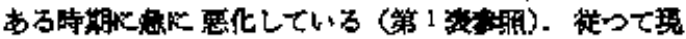

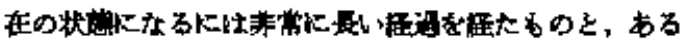

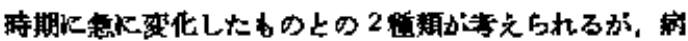

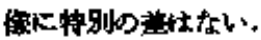

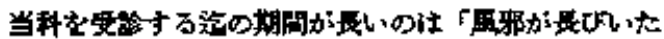

第 1 部

\begin{tabular}{|c|c|c|c|c|c|c|c|c|c|}
\hline \multirow{2}{*}{ 展 } & \multirow{2}{*}{ W煎 } & \multirow{2}{*}{ 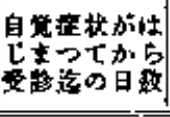 } & \multirow{2}{*}{ 爑 行 } & \multirow{2}{*}{ 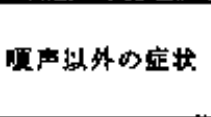 } & \multirow{2}{*}{ 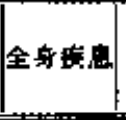 } & \multirow{2}{*}{ 䎾: } & \multicolumn{2}{|l|}{ 浩 } & \multirow{2}{*}{ 予 竦 } \\
\hline & & & & & & & 育 & 手街的 & \\
\hline 1520 & 主禹 & 1 年的月 & 锞 & 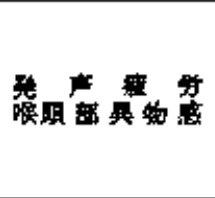 & 42 & & 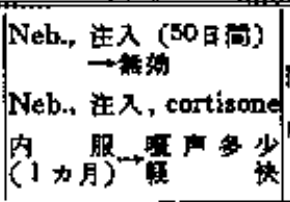 & 相 & : \\
\hline 2017 & 主雾 & 2年6カ月 & $\Rightarrow$ & 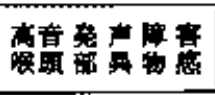 & 高船压定 & $\neq \mathrm{L}$ & 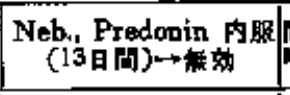 & 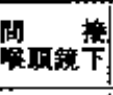 & 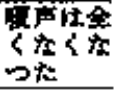 \\
\hline 3,470 & 荎䘨 & 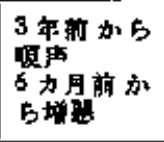 & 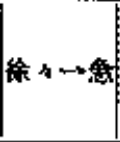 & 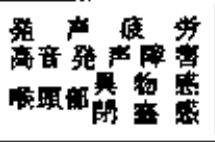 & t5 $\mathrm{L}$ & t纪 & Neb. $\rightarrow$ - & 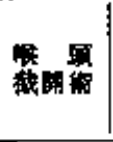 & 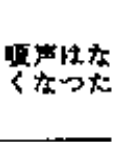 \\
\hline 4628 & 知 & 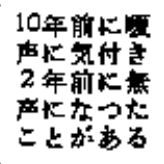 & 棻々ー急 & 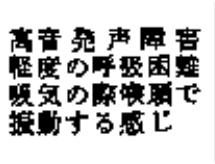 & 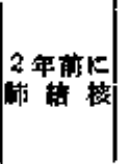 & $\neq L$ & $\Leftrightarrow$ & 林氏法 & 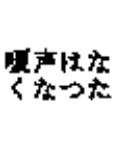 \\
\hline
\end{tabular}

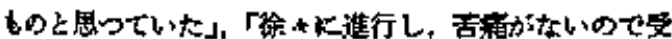

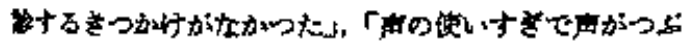

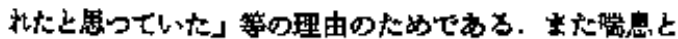

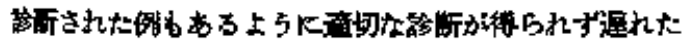
都ある。

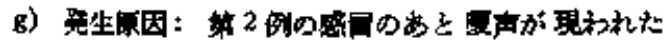

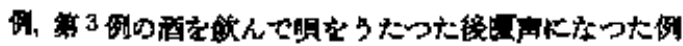

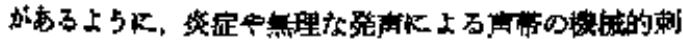

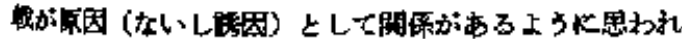

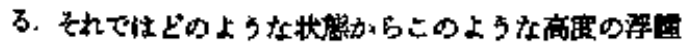

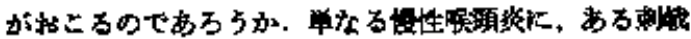

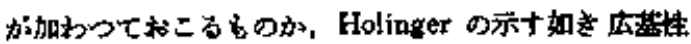

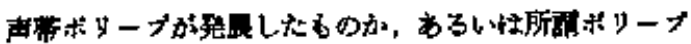

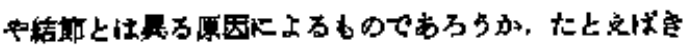

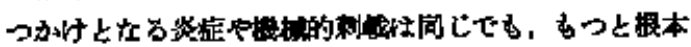

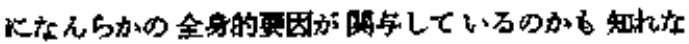

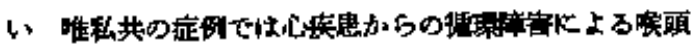

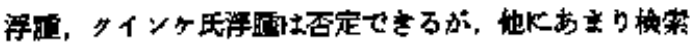

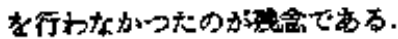

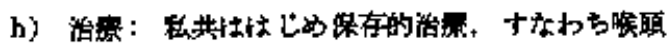




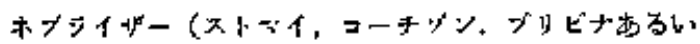

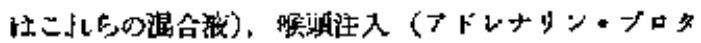

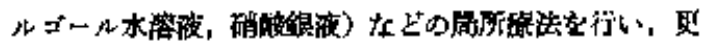

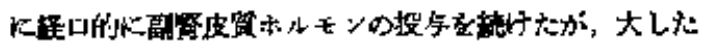

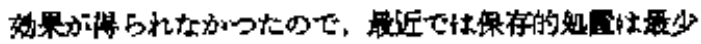

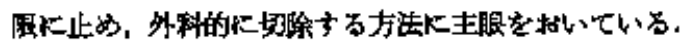

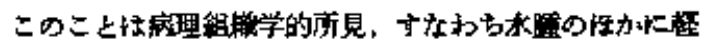

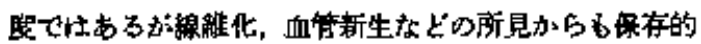

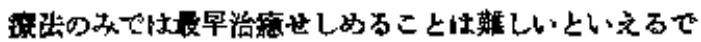

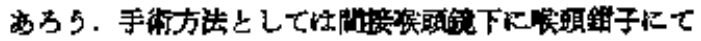

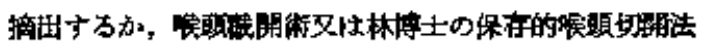

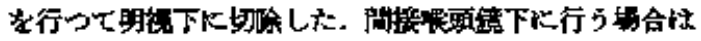

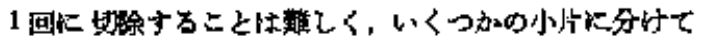

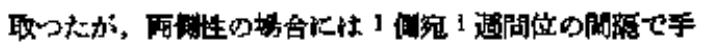

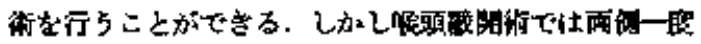

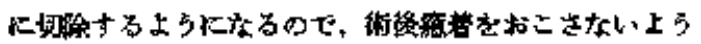
な注续が为要である.

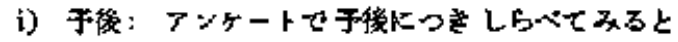

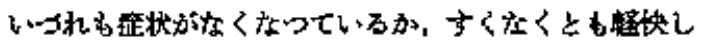

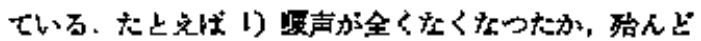

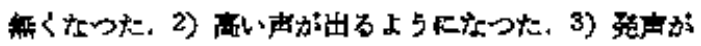

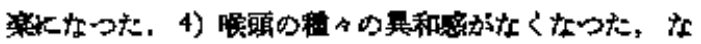

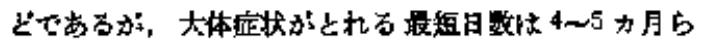
LW.

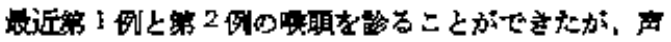

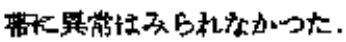

4)庑理䋧杸学的所見

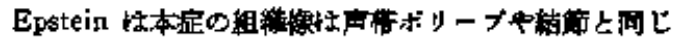

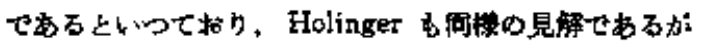

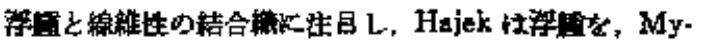

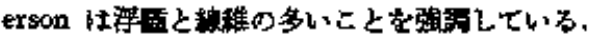

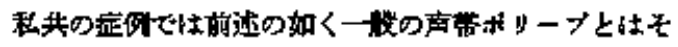

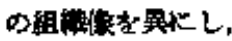

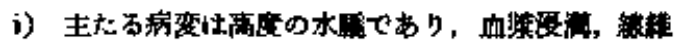

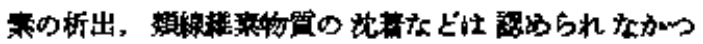

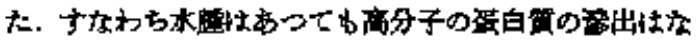

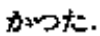

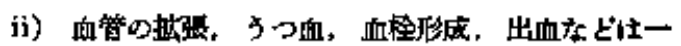

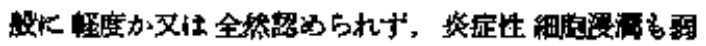
is

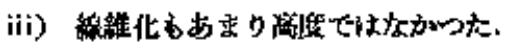

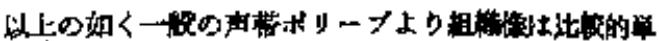

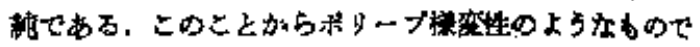

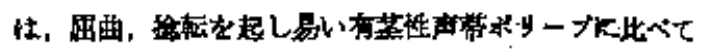

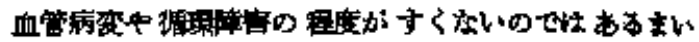

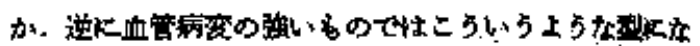
らないのではいなろらか.

\section{V 呚}

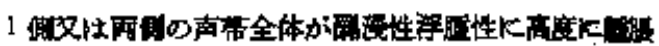

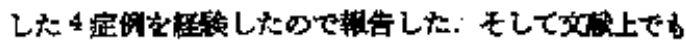

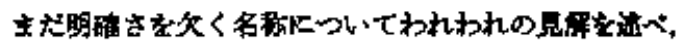

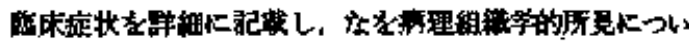

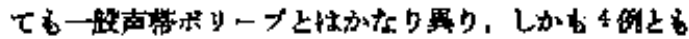

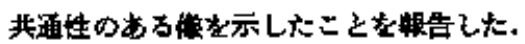

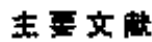

1) Epsteit, S.S: The vocal cord polyp, J. Lar. yng. \& Otol. 21 : 673, 1957.

2) Hajek, M.i Bej. trlige zur Anatomie der Stimmlippen, $Z$. Hals-, Nasen- u Ohrenheilk. 13: 161, 1925, 3) Holinger, P.H; Pathology of the larynx, Ann. Otol. Rhin. \& Larjng. 56; 583, 1947. 4) Hollingor, P.H. \& Johnston, K.C.: Benign tumors of the ferynx, Ann. Otol. Rhin. \& Laryng. 60:496, 1951. Myerson, M.C.: Smokex's larynx, Ann. Otol. Rhin. \& Laryng, 59:541, $1950 . \quad$ 6) New, G.B. \& Erich, J.B.: Benign tumors of the laryax, Arch. Oto-

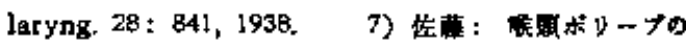

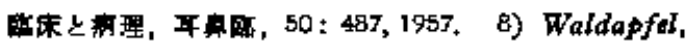
R.: Pathology of the subepithelial layer of the vocal cords, Ann. Otol. Rhin. \& Laryng. 49:647, 1940 .

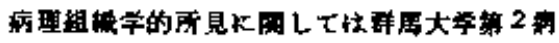

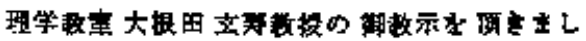

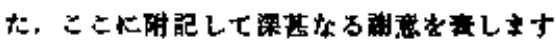

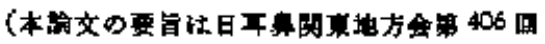

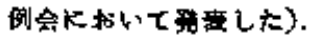

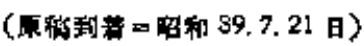




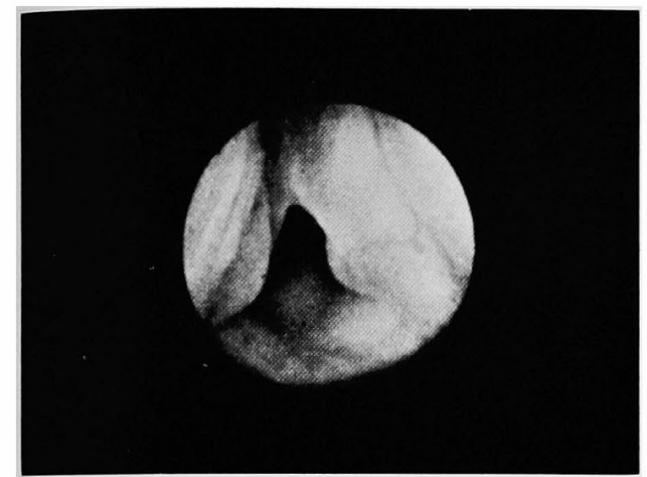

第 3 図症例 4 の喉頭像（写真）

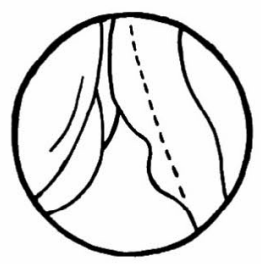

第 4 図 前図の説明図で点線は本来

の声帯の游離绿の位置を示す.

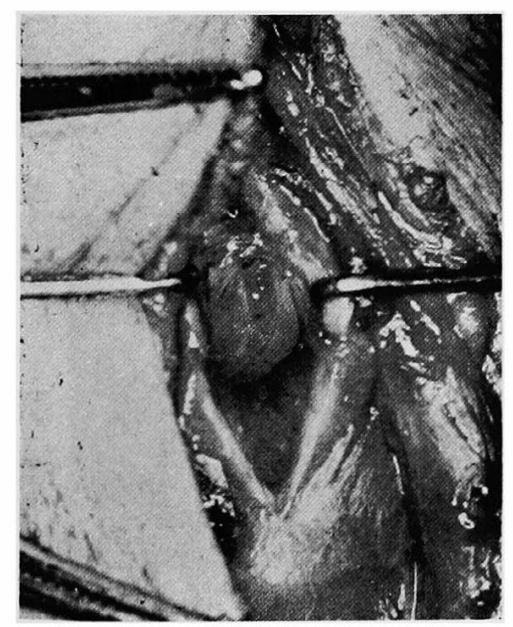

第 5 图声門下上りみた声帯の腫脹で本来 の声且の形は全く失われている.

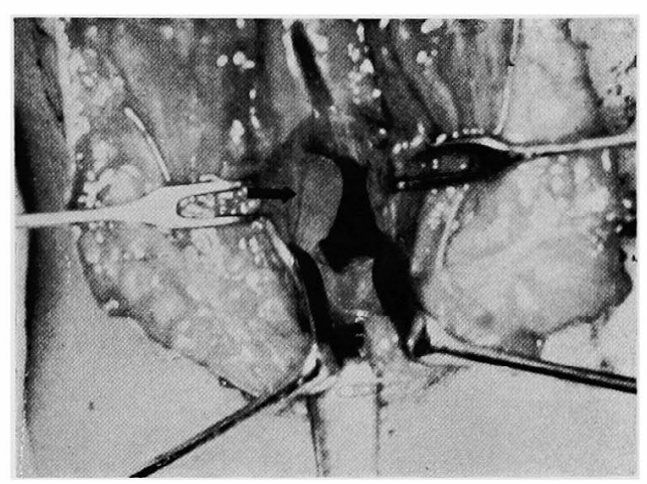

第 6 図 矢印は Linea arcuata inf. を示す

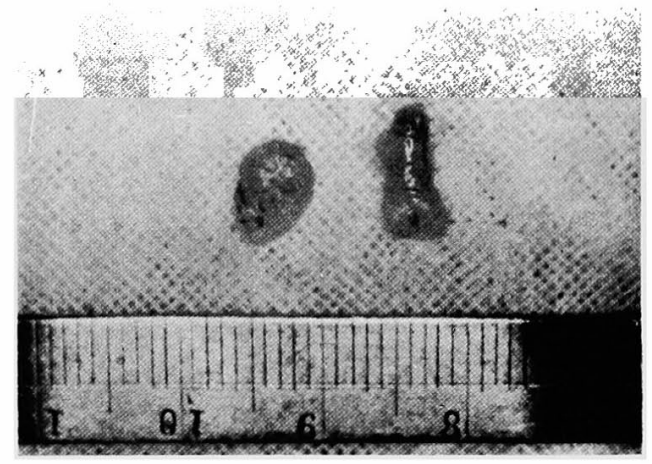

第 7 図第 5 図に示した症例の切除標本

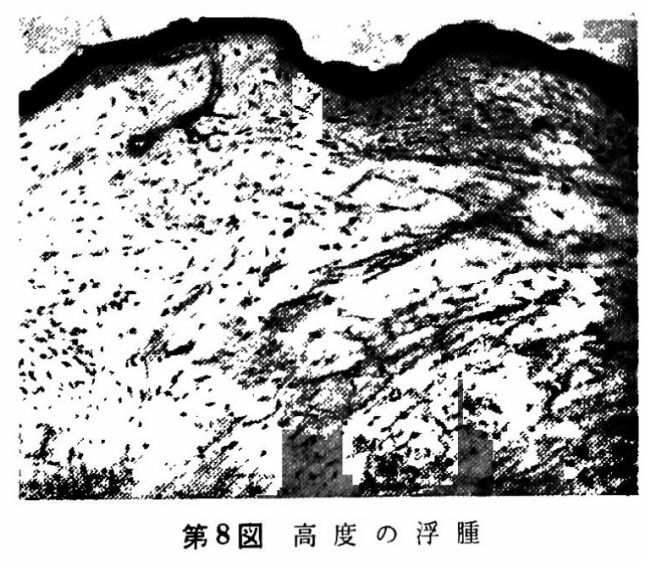




\section{石井・馬場論文・附図}

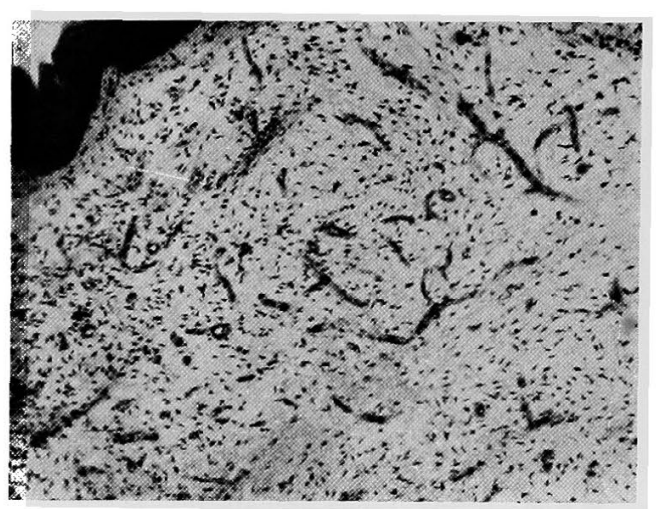

第9図毛細血管の新生像

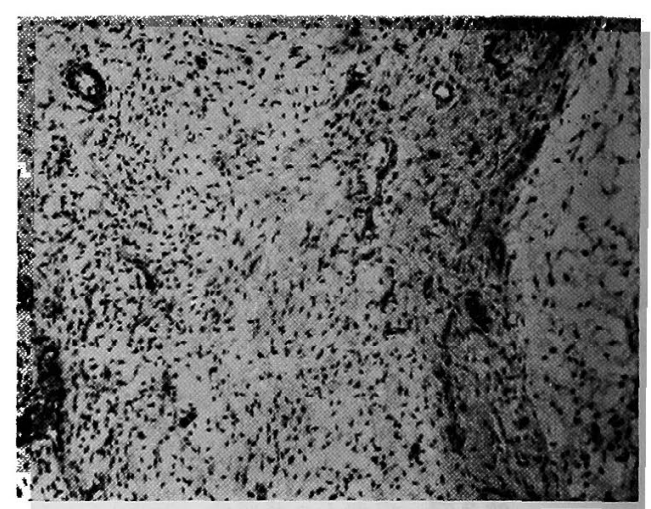

第 10 図線維芽細胞や結合織線維 の密在を示す
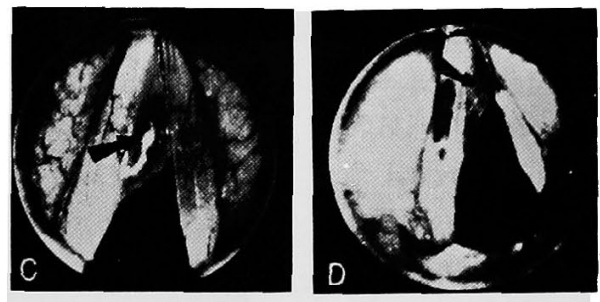

第 11 図 Holinger (1951) より引用.

一印は腫脹を示す。（著者）
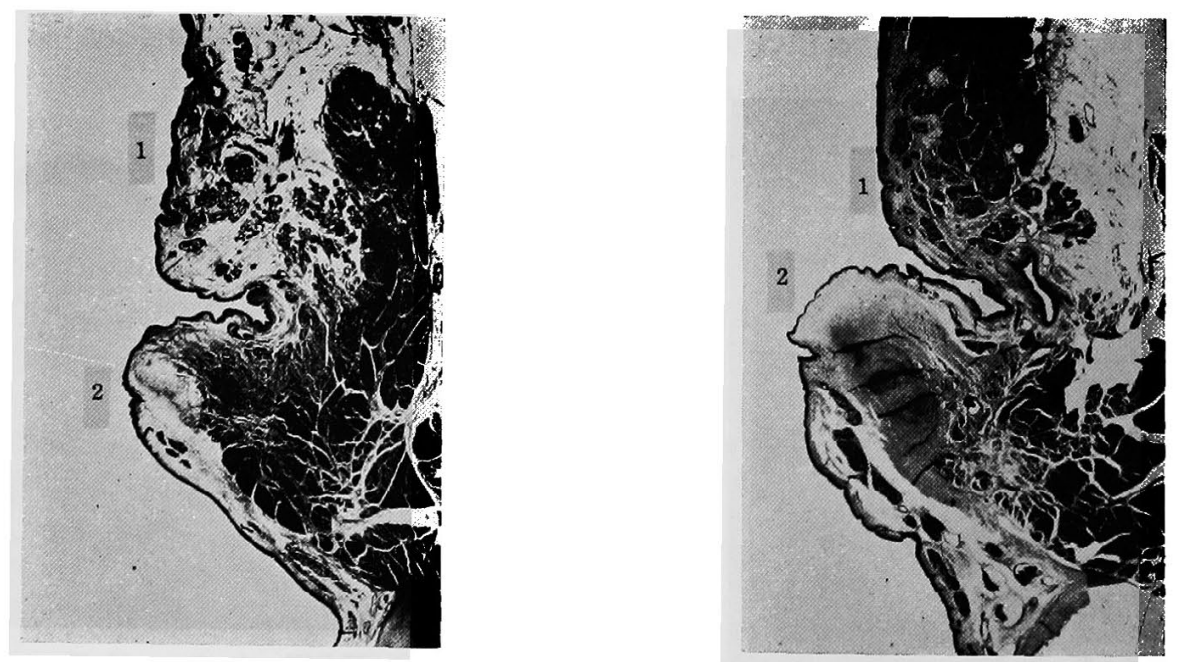

第 12 图左は正常喉頭の前頭断面, 右は本症類似の疾患で 声帯は高度の浮腫を示している
1. 仮声帯
2. 声帯 